\title{
E-BUSINESS USAGE ACROSS AND WITHIN FIRMS IN THE UK*: PROFITABILITY, EXTERNALITIES AND POLICY
}

by

\author{
Giuliana Battisti*, The University of Nottingham \\ Alessandra Canepa, Brunel University \\ and \\ Paul Stoneman, The University of Warwick
}

\begin{abstract}
Using data from the third UK Community Innovation Survey we model the usage of e-business across and within firms in the UK in the year 2000 as a single observation upon an integrated process of inter- and intra-firm diffusion. The intra-firm dimension is a significant extension to standard analysis. The model estimates indicate that the pattern of ebusiness usage reflects the heterogeneity of firms in terms of size, other innovative activity and labour force skills (generating differences in the payoffs to use) as well as market and non-market intermediated externalities. The policy implications of the findings are discussed.
\end{abstract}

\section{JEL Classification: O3}

Key Words: Technological diffusion, e-business, technology policy

- Giuliana Battisti , Industrial Economics division, Nottingham University Business School, The University of Nottingham, Jubilee Campus, Wollaton Road, Nottingham NG8 1BB, United Kingdom. Tel. ++44 (0)115 8466128, E-mail: giuliana.battisti@nottingham.ac.uk 


\section{INTRODUCTION}

The impact of the Internet upon the cost and speed of information access will probably prove in time to make it one of the most important innovations of the last hundred years. One aim of this paper is to understand the process by which this new technology has been adopted by firms and in particular to explore not only usage per se but the extent or sophistication with which the technology has been or is being used. The main theoretical tools for this exercise derive from prior studies of the diffusion of new technologies. The data available comes from the third UK Community Innovation Survey (CIS3) and is a single cross section rather than a panel, thus we cannot estimate a full dynamic diffusion model; however the model gives clear predictions as to what differences might be expected between firms and industries at a single point in time, which may be tested. The diffusion literature mainly concentrates upon the extensive margin (use across firms) with a growing literature on inter-firm diffusion (see, for example, the recent survey by Hall, 2004). There is a much smaller literature on the intensive margin (use within firms) or intra-firm diffusion (see, Battisti and Stoneman, 2005), although the relative importance of both in the overall diffusion process has been shown by Battisti and Stoneman (2003). Usually however the two margins are discussed and analysed separately. A second contribution of this paper is to offer an integrated approach that combines analysis of both the intensive and extensive margin. This also allows us to consider the impact upon the extent of use of e-business across and within firms of market intermediated and non-market intermediated externalities after controlling for a number of firm characteristics and environmental factors, which then enables policy discussion.

The data source is discussed in section 2 and used to provide an overview of e-business use in the UK. In section 3 a simple integrated inter- and intra-firm diffusion model is presented. In section 4 this is applied to the data and the drivers of e-business use isolated. The policy implications of the results are discussed in section 5. Section 6 contains conclusions.

\section{THE COMMUNITY INNOVATION SURVEY}

Ideal data for the exercise performed here would be a long and thick panel. There are in fact now considerable data on the use of e-commerce in Europe collected as part of the EC eBusiness Market W@tch observatory initiative. In the UK this involves the e-commerce survey that has been conducted by the Office of National Statistics, from which data on ICT usage are available annually for the period 2001-2005 (although the 2001 data are poor) and for which we have been allowed access to the individual returns. There are two main problems with these data. First, there are no data on firm characteristics and these have to be 
observed by cross reference to the ABI/ARD2 data sets. ${ }^{1}$ We found however that there are only 157 firms for which one can obtain full data on e-business usage and other relevant characteristics for the period 2001-2004, which is too small to be useful here. Secondly, even the supplemented data do not contain measures of other innovation indicators to be found in the CIS data and that we use below as important control variables.

We have thus used responses to the third ${ }^{2}$ UK Community Innovation Survey (CIS3) which employed a pan-European survey instrument designed to gather information on the extent of innovation in European firms. This was carried out in the UK in 2001 by the Office of National Statistics on behalf of the Department of Trade and Industry (now BERR- the department of Business Enterprise and Regulatory Reform) and anonymised individual returns data has been made available to $\mathrm{us}^{3}$. The advantage for current purposes of the CIS3 data is that it contains data upon both the extensive and intensive margin of e business usage in addition to data upon other indicators of innovativeness and firm characteristics. The CIS3 survey was addressed to enterprises (which we here call firms, although this is misleading for multi-plant firms) with more than 10 employees, in both manufacturing and service industries and related to innovative activities between 1998 and 2000. From an original sample of 126,775 records on the Inter Departmental Business Register, the questionnaire was sent to a stratified (by industry and firm size) sample of 19,602 enterprises and 8,173 responses were eventually registered, which represent the sample for the work reported here. We have no reason to believe that there are any particular biases in this final sample.

In CIS3, Question 17.2 is:

17.2 Can you indicate the extent of your enterprise's use of e-business activities over the period 1998 - 2000 (please tick all that apply)

a. Basic Internet presence

b. Internet used for information

c. Customers can place orders through the Internet site

\footnotetext{
${ }^{1}$ See www.statistics.gov.uk/about/data/guides/productivity/downloads/ProductivityHandbook Chapter10.pdf on such procedures.

${ }^{2}$ An earlier CIS2 survey did initially hold out the prospect of a panel data set, however the relevant question asked in that survey did not identify the intensive margin and the extent of overlap between the two samples is small. Although we make some use of the CIS2 data it is therefore in a supportive rather than central way. We also explored the possibility of constructing a panel using CIS4. Unfortunately the relevant questions on internet use were dropped from CIS4 (because they were included in the e-commerce survey).

${ }^{3}$ For which we are most grateful to the DTI (as was).
} 


\section{d. Commerce with other businesses through the Internet site}

The list of offered responses to Q 17.2 does not include a 'no use' choice. Although there may be non-respondents to this question for other reasons, we measure non-users (and thus the extensive margin) by the number in the sample of non-respondents to this question. In order to check upon the validity of this we explored the proportion of firms who claimed in CIS2 to be using the Internet (34\% of the sample), who also replied to CIS3 (243) but did not respond to Q17.2. Of the 243 firms only 13 (mostly small firms with little other innovative activity) did not respond to Q17.2, which leads us to believe that any error introduced by our assumption that non-response means non-use will be small. Of the total sample of 8173 enterprises there are 1376 non-respondents/non-users. Thus we estimate that $83.2 \%$ of all enterprises in 2000 were engaged in e-business to some degree. As a check, the e-commerce survey for 2005 estimates that $78.8 \%$ of businesses were using the internet to some degree in 2002 and $88.8 \%$ in $2005^{4}$.

Intra-firm diffusion (or the intensive margin) is often measured by indicators such as the proportion of the firm's capital stock that embodies the new technology, or the proportion of output produced using the new technology, or, in the current situation, the proportion of employees connected to the internet. Our data source does not provide information on such measures but does enable one to consider the intensive margin via a different metric. As ebusiness spreads, one might not only expect the number of users in the firm to increase but also the range of tasks that they perform using the technology (additionally or alternatively) to increase, and/or the tasks that they perform using the technology to increase in sophistication (see Forman et al. 2002, 2003 and later Crespi et al. 2004 for a similar approach). It is the latter definition that we adopt to define the metric for intra-firm diffusion.

There is some dispute in the literature as to whether one can devise a simple index of sophistication of use (see for example Bridgewater and Arnott, 2004). In this paper we are restricted by the data available and cannot proceed other than by interpreting the responses already made to Q17.2. These responses cover four different uses to which responses are requested. Response (a) may just mean that the firm has an ISP whereas (b) may just mean that the firm has done a Google search, and we do not consider one can judge either as more sophisticated than the other. Response (d) essentially means that the firm has purchased via the web whereas response (c) essentially means that the firm has sold through the web. Although we may infer that these latter two activities are more 'enhanced' than the first two

\footnotetext{
${ }^{4}$ Source: www.statistics.gov.uk/downloads/theme_economy/ecommerce_report_2005.pdf, Table 12.
} 
one cannot necessarily order (c) and (d) in terms of sophistication. It was suggested to us that one may consider sophistication by considering some activities as natural precursors to others, e.g. (a) and (b) would be natural precursors to (c) and (d). However we do not see (a) as a natural precursor to (b) nor (c) as a precursor to (d), nor vice versa. It has also been suggested to us that we consider responses to (a), (b) (c) and (d) separately and allow the empirical method to order patterns of sophistication. Unfortunately respondents did not necessarily take on board the instruction to tick all that apply, and thus we were unable to proceed in this way either. In fact of the sample of 8173 firms, in response to Q17.2, 63.4\% ticked (a), 64.8\% ticked (b), 16.5\% ticked (c), 17.3\% ticked (d) and 8.2\% ticked both (c) and (d).

In these circumstances we define for empirical purposes just two categories of e-business usage upon the reasoning that we can be sure that (c) and/or (d) are more sophisticated than (a) and/or (b) but little else. The two categories (Category 0 being non-use) are:

Category 1: Basic usage, shown by indicating (a) and/or (b) but not (c) nor (d);

Category 2: Enhanced usage, shown by indicating (c) and/or (d).

We have assumed that all firms in Category 2 also have a basic Internet presence that would seem to be nested in the former. Thus users in categories 1 and 2 represent the extensive margin whereas the proportion of users in category 2 indicates the intensive margin.

\section{[Table 1 in about here]}

Table 1 presents some of the detailed information upon the pattern of inter- and intra-firm usage of e-business in 2000. The data are presented as proportions of the sample of enterprises that fall into categories 0,1 or 2 . The data indicate that in $2000,83.2 \%$ of the sample use the internet to some degree with $57.5 \%$ being basic users and $25.6 \%$ being enhanced users (which may be compared to the US figures estimated by Forman et al. (2002) of $88.6 \%$ of the sample being users and $12.6 \%$ being enhanced users). The extent of use (from $71.2 \%$ to $94.9 \%$ ) and the extent of enhancement (from $11 \%$ to $32.3 \%$ ) differ across industries (listed in Appendix 1) and firm size as measured by number of employees. Although not strictly comparable, the data in the e-commerce survey ${ }^{5}$ show similar patterns of limited sophisticated use and similar differences across firm size and industrial sectors.

These data indicate inter alia that inter-firm usage is an incomplete indicator of the overall usage of a new technology, for although in $200083.2 \%$ of firms consider themselves to be e-

\footnotetext{
5 www.statistics.gov.uk/downloads/theme_economy/ecommerce_report_2005.pdf, Tables 21 and 22.
} 
business users, only $26 \%$ are using the technology at anything other than a basic level. This justifies looking at both margins. In addition inter-firm usage is not necessarily a reliable indicator of the extent of intra-firm usage and thus data on the latter contain new information.

\section{AN INTEGRATED DIFFUSION MODEL}

The diffusion literature has tended to model inter- and intra-firm diffusion separately, developing and applying quite distinct models. We propose an alternative approach where both the intensive and extensive margins are approached simultaneously (earlier attempts at this are to be found in Battisti, 2000, and Battisti and Stoneman, 2003, 2005).

Most of the limited intra-firm literature builds upon the seminal work of Mansfield (1963, 1968) based upon an epidemic learning process.

This is a disequilibrium type model whereby diffusion is a process of adjustment to a fixed end point deriving from uncertainty reduction via information spreading as a result of prior usage.

Such epidemic approaches incorporate non-market intermediated externalities. Stoneman and Battisti (1997) and later on Battisti (2000) have shown that this approach provides only a partial explanation (if any) of the intra-firm process and that an equilibrium profitability based approach can provide a better explanation of the diffusion process.

Karshenas and Stoneman (1993) classify the inter-firm equilibrium models present in the literature into three main approaches. Their common ground is that at a point in time diffusion extends only to the point where it is profitable (or most profitable) to adopt the new technology. Over time the cost of adoption, or the size of returns, or the distribution of returns (across potential users) change, and the diffusion path is then mapped out. However in the three approaches there are different main determinants of profitability. The first are rank effects in that firms have different characteristics and thus different returns. The second are stock effects whereby one firm's adoption impacts (negatively) upon the profitability of further adoption by others (and also the profitability of existing adopters). Finally there are order effects, where returns are determined by positions in the order of adoption and one firm's adoption reduces the returns to all other non-adopters as they are moved down the order. The latter two effects represent market intermediated externalities. 
Following Karshenas and Stoneman (1993) we believe that there is considerable advantage in constructing an encompassing model reflecting different strands in the literature and then letting the data indicate what is, and is not, empirically relevant. The model we present is a reduced form and is built around the view that the firm will adopt new technology up to the point where the marginal expected gross profit gain from first use or further use equals the marginal expected cost taking into account rank stock, order and epidemic effects.

For simplicity, assume that the potential investor has myopic expectations on both adoption costs and the gross profit gains (see Ireland and Stoneman, 1986, for a relaxation of this assumption) and is risk neutral (see Stoneman, 1981, for a more formal model with uncertainty), with all potential adopters being price takers. Define $\Pi_{\mathrm{ij}}(\mathrm{t})$ as the gross expected profit gain in time $t$ to firm $i$ in industry $j$ from (i) the use of a first unit of a new technology if a non-user or (ii) the extension of use of a new technology by one unit if already a user. The profit gains from using and extending e-business use may arise from a number of different sources such as increases in market shares, increased selling prices, reduced marketing costs and/or processing costs, etc.

Reflecting the nature of the technology and the several different theoretical approaches to diffusion summarised above, we assume that $\Pi_{\mathrm{ij}}(\mathrm{t})$ is a function of the following.

(i) $\quad x_{i}(t)$, the extent of usage of the new technology by firm $i$ in time $t$ (which for a nonuser will be zero). Allowing own use to impact upon the marginal gain from adoption is innovative in the intra-firm literature and essentially extends the inter-firm concept of stock effects associated with Reinganum (1981) and the inter-firm order effect associated with Fudenberg and Tirole (1985) through to the intensive margin. These effects would imply that $\mathrm{x}_{\mathrm{i}}(\mathrm{t})$ would impact negatively on the expected gross profit gain from further adoption. However there may also be positive effects via internal network externalities and thus the overall impact may be positive or negative depending on the strength of stock and order vs. the network effects. We do not believe e-business to have particularly strong internal network effects, and thus expect the overall effect to be negative - in fact if the overall impact were positive then the firm would only choose corner solutions (zero usage or 100\% usage) and not intermediate usage.

(ii) firm characteristics, yet to be specified (a vector $\mathbf{F}_{\mathbf{i}}(\mathrm{t})$ ), extending the inter-firm concept of rank effects associated with probit models of inter-firm diffusion to the intra-firm case.

(iii) other industry characteristics (a vector $\mathbf{F}_{\mathbf{j}}(\mathrm{t})$ ) reflecting further rank effects. 
(iv) the extent of industry usage of new technology $\left(\mathrm{y}_{\mathrm{j}}(\mathrm{t})\right)$, reflecting between-firm stock and order effects, upon the basis that the payoff to the firm depends upon what other firms are doing, and external network effects. The first two of these effects are generally expected to be negative, but the latter, network effect is expected to be positive and overall the effect may go either way.

(v) two 'experience' terms, to reflect epidemic arguments, the first being a measure of the firm's own experience, $\mathrm{E}_{\mathrm{i}}(\mathrm{t})$, (often proxied by time since own first adoption) the second being the experience that the firm gains from observing other users, $E_{j}(t)$, (often proxied by the extent of diffusion in time $t$ ).

Summarising, we thus write that:

$$
\prod_{\mathrm{ij}}(\mathrm{t})=\prod_{\mathrm{ij}}\left(\mathrm{x}_{\mathrm{i}}(\mathrm{t}), \mathbf{F}_{\mathrm{i}}(\mathbf{t}), \mathbf{F}_{\mathrm{j}}(\mathrm{t}), \mathrm{y}_{\mathrm{j}}(\mathrm{t}), \mathrm{E}_{\mathrm{i}}(\mathrm{t}), \mathrm{E}_{\mathrm{j}}(\mathrm{t})\right)
$$

Define $P_{i}(t)$ as the expected (annual) adoption cost to firm $i$ in time $t$ of a unit of new technology. If the firm was previously a non-user then this is the cost of buying a first unit of the technology. If the firm is an existing user then this is the cost of an enhancement of the activities being undertaken. In principle enhancement and first adoption costs may differ from each other but we consider the unit measure to be such as to make them equal. $\mathrm{P}_{\mathrm{i}}(\mathrm{t})$ is made up of two parts, one that reflects costs common to all buyers (e.g. the price of machines), $\mathrm{P}(\mathrm{t})$, and the other that reflects firm-specific effects such as adjustment and installation costs, $e_{i}(t)$, i.e. $P_{i}(t)=P(t)+e_{i}(t)$. It has been suggested to us that the cost of first use or enhancement may be larger for large firms, which is possible, but this will be picked up by this approach if $e_{i}(t)$ is allowed to be affected by a firm-size variable yet to be specified.

A firm will introduce a unit of the new technology or enhance usage if the profit gain from so doing (given myopia) exceeds the cost, i.e. if $\prod_{\mathrm{ij}}(\mathrm{t}) \geq \mathrm{P}_{\mathrm{i}}(\mathrm{t})$. Defining $\mathrm{x}_{\mathrm{i}}(\mathrm{t}) *$ to satisfy $(2)$ :

$$
\prod_{\mathrm{ij}}\left(\mathrm{x}_{\mathrm{i}}(\mathrm{t})^{*}, \mathbf{F}_{\mathrm{i}}(\mathbf{t}), \mathbf{F}_{\mathrm{j}}(\mathbf{t}), \mathrm{y}_{\mathrm{j}}(\mathrm{t}), \mathrm{E}_{\mathrm{i}}(\mathrm{t}), \mathrm{E}_{\mathrm{j}}(\mathrm{t})\right)=\mathrm{P}_{\mathrm{i}}(\mathrm{t})
$$

it can be shown that

$$
\mathrm{x}_{\mathrm{i}}^{*}(\mathrm{t})=\mathrm{G}\left\{\mathbf{F}_{\mathrm{i}}(\mathbf{t}), \mathbf{F}_{\mathrm{j}}(\mathbf{t}), \mathrm{y}_{\mathrm{j}}(\mathrm{t}), \mathrm{E}_{\mathrm{j}}(\mathrm{t}), \mathrm{E}_{\mathrm{i}}(\mathrm{t}), \mathrm{P}_{\mathrm{i}}(\mathrm{t})\right\}
$$

Where $\mathrm{x}_{\mathrm{i}}{ }^{*}(\mathrm{t})$ is the firm's desired or optimal level of use of the new technology at time $\mathrm{t}$. 
The essence of a diffusion model is that it is dynamic, providing insights into the spread of a technology over time. That is the character of the above model with the desired extent of inter- and intra-firm diffusion extending over time as either $\mathrm{P}_{\mathrm{i}}(\mathrm{t})$ declines or $\mathbf{F}_{\mathbf{j}}(\mathbf{t}), \mathbf{F}_{\mathbf{i}}(\mathbf{t}), \mathrm{E}_{\mathrm{i}}(\mathrm{t})$, $E_{j}(t)$ or $y_{j}(t)$ change. However the data available to us are a single cross-section that provides one snapshot of the state of that dynamic process in the year 2000. It is thus obviously not possible to explore the dynamics of the process to any degree. Instead, we intend to use the model to predict the factors that should be considered as determinants of inter- and intra-firm usage in the year 2000. The cross-section approach is also used by Forman et al. (2002, 2003), Hollenstein (2004) and Battisti et al. (2007) in similar analyses.

In the absence of any insight or data that would enable us to explore any divergence between $\mathrm{x}_{\mathrm{i}}(\mathrm{t})$ from $\mathrm{x}_{\mathrm{i}}{ }^{*}(\mathrm{t})$ arising, for example, from some time-intensive adjustment process, we proceed by assuming that $\mathrm{x}_{\mathrm{i}}^{*}(\mathrm{t})=\mathrm{x}_{\mathrm{i}}(\mathrm{t})$, although in the presence of divergences such an approach will yield biased estimates. We can then write (3a) as (3) where, given we have a single cross-section, all time subscripts have been removed:

$$
\mathrm{x}_{\mathrm{i}}=\mathrm{G}\left\{\mathbf{F}_{\mathbf{i}}, \mathbf{F}_{\mathbf{j}}, \mathrm{y}_{\mathrm{j}}, \mathrm{E}_{\mathrm{i}}, \mathrm{E}_{\mathrm{j}}, \mathrm{P}_{\mathrm{i}}\right\} .
$$

Of the variables included in (3), $\mathrm{E}_{\mathrm{i}}$ is a variable that reflects the firm's own experience of the new technology, but in a single data cross-section it is not possible to measure this. $\mathrm{P}_{\mathrm{i}}=\mathrm{P}+\mathrm{e}_{\mathrm{i}}$ and $\mathrm{P}$ is the same for all firms and thus implicitly considered as included in the constant term (and will be ignored from this point on); $\mathrm{e}_{\mathrm{i}}$ will differ across firms, but these cost impacts on the firm cannot be separated out from the revenue impact of firm characteristics and are thus considered as incorporated in the impact of firm characteristics $\left(\mathbf{F}_{\mathbf{i}}, \mathbf{F}_{\mathbf{j}}\right)$ upon $\mathrm{x}_{\mathrm{i}}$. To measure the firm and industry characteristics $\left(\mathbf{F}_{\mathbf{i}}, \mathbf{F}_{\mathbf{j}}\right)$ we use the following indicators:

(i) Firm size, measured by the number of employees ${ }^{6}$ divided by 5 (Employ98). Size may pick up a number of other firm characteristics such as efficiency, management abilities, perhaps past innovations or variations in the costs of acquiring the new technology and any scale economies, e.g. a software only has to be written once, whatever the number of users. Firm size has a long history as a positive and deterministic factor in diffusion studies (see for example Mansfield, 1968; Hannan and MacDowell, 1984; Karshenas and Stoneman, 1993 Colombo and Mosconi, 1995; and Astebro, 2002). Data are available on size for both 2000 and 1998 and we have chosen 1998 in order to better avoid endogeneity problems (see below).

\footnotetext{
${ }^{6}$ Division by 5 is done purely to make the coefficient larger and more easily reportable.
} 
(ii) Dummy variable indicators of firms' innovativeness ProdNov and ProcNov, taking the value one if the firm introduced a product or a process new to the market between 1998 and 2000 and zero otherwise. These variables should reflect the fact that firms that adopt innovative work practices and/or products are more prone to adopt ad-hoc technological innovations in support of their activities (see Pil and MacDuffie, 1996; Bresnahan et al., 2002; Battisti et al., 2005; etc.). Therefore, they are believed to be good predictors of the use of e-business.

(iii) $\mathrm{R} \& \mathrm{D}$ Intensity $R \& D$, which takes the value one if the firm reports $\mathrm{R} \& \mathrm{D}$ activity in the period 1998-2000 and zero otherwise. This variable reflects the Schumpeterian hypothesis that formalised $R \& D$ exerts a positive impact upon the use of a technology, in line with Cohen and Levinthal (1989).

(iv) Dummy variables Mngt, which takes the value one if the enterprise indicated that advanced management techniques (e.g. knowledge management, quality circles) were introduced during the period 1998-2000 and zero otherwise, and Org, which takes the value one if the enterprise indicated that major organisational structures (e.g. investors in people, diversification) were introduced during the period 1998-2000 and zero otherwise. These variables reflect the argument that managerial innovations may be complementary to the use of other technologies and therefore enhance the use of e-business (for empirical evidence in support of this hypothesis see, for example Colombo and Mosconi, 1995; Brynjolfsson et al., 2002; Greenan, 2003; Black and Lynch, 2004).

(v) The covariates PropSci and PropOth, measuring the proportion of the firm's employees with a degree in 2000 in (a) science and engineering subjects and (b) other subjects. The importance of skills has been emphasised by, for example, Finegold and Soskice (1988), Bartel and Lichtenberg, 1987; Caroli and Van Reenen, 2001; and Bresnahan et. al., 2002; etc.

(vi) A series of industry dummy variables to reflect environmental factors such as different industry conditions, markets, and types of innovations and payoffs to firms in different industries $\left(\mathrm{SIC}_{\mathrm{j}}\right)$. The industrial classification follows the SIC-92, but the industries have been grouped into $\mathrm{j}$ wider subgroups as defined in Appendix 1.

The final variables to measure pick up the effects on firm i of diffusion taking place in other firms: $y_{j}$ reflecting stock, order and network effects and $E_{j}$ reflecting epidemic-type learning. In the absence of time-series data, within sample variance is introduced by arguing that these variables are industry-specific. The only available proxies for measuring these effects are variables that reflect the extent of industry usage. We argue that industry usage is made up of both the breadth and depth of use and two indicators are thus required. These indicators are: 
(vii) Inter $r_{\mathrm{j}}$, the proportion of firms in the industry who have adopted e-business (i.e. both basic and enhanced, measured as $100 \%$ minus the proportion of non-users).

(viii) Intra $\mathrm{j}_{\mathrm{j}}$, the proportion of firms in the industry who fall into the category of having an enhanced level of e-business usage.

Jointly the coefficients upon these variables measure the combined impacts of $y_{j}$ and $E_{j}$. Although it is innovative to argue that the intensive margin may be affected by the extensive margin and vice versa, unfortunately the approach will not enable separation of the stock, order and network effects (market intermediated externalities) from the learning effects (nonmarket intermediated externalities). However, the sign(s) of the coefficients on the two variables used will enable some insight into (i) whether there are externalities and (ii) whether the stock and order effects are stronger or weaker than the network and learning effects. As it improved numerical stability of the model without significantly affecting other parameter estimates, these variables were entered as logit transformations.

\section{ESTIMATES}

We have estimated the diffusion model presented in the previous section in two ways (with results reported in sections 4.1 and 4.2 below). The first is a traditional bivariate logit version reflecting standard inter-firm diffusion modelling of the decision to adopt e-business, i.e. the extensive margin. The second is a multinomial specification to model the extent of use of ebusiness by the adopting firms, i.e. the intensive margin. Following Battisti and Stoneman (2003, 2005) we use the same covariates (as detailed in equation 3) for both model specifications. This allows comparison and contrast between the different effects upon both the adoption and the extent of use of e-business by firms in the sample.

For both models the sample size is 5822 of the original 8173, a reduction resulting from missing data points. ${ }^{7}$ Initial estimates of a fully loaded model indicated a number of industry dummy variables that were not significant and thus we proceeded with the estimation of a more restricted model. In the literature (see Mickey and Greenland, 1989, for example) that for logistic regression the use of a $p$-value $=0.05$ often fails to identify variables known to be important and we thus follow the recommendation that the 0.25 level be used as a screening criterion for variable selection.

\footnotetext{
${ }^{7}$ A number of statistical tests have been carried out to test for possible sample selection bias. We found no statistical differences between the distribution of the key variables in the reduced (5822) and full sample (8173). The same can be said of the distribution of firms across industries and of the distribution over non-use, basic use and enhanced use (details available from the authors upon request).
} 


\subsection{The extensive margin}

For the bivariate logit estimates of the model detailed in equation (3) $\mathrm{x}$ takes the value 1 if the firm is an adopter in/by 2000 (i.e. a Category 1 or Category 2 user) and zero otherwise (i.e. the firm is a non-user). At this date $83 \%$ of the sample had already adopted e-business to some degree thus in inter-firm terms the sample is very late in the diffusion process and we thus expected many of the effects to be downplayed relative to what might have been found at an earlier date. For this model the predictive power has been determined estimating the ROC (Receiver Operating Characteristic) curve for non-users versus users (for a review of ROC techniques, see Green and Swets, 1974). In Figure 1 we report on the y-axis the 'Sensitivity', measured by fraction of adopters $x_{\mathrm{j}}=1$ correctly classified while on the $\mathrm{x}$-axis we report ' 1 Specificity', measured as the fraction of non adopters, $x_{\mathrm{j}}=0$, wrongly classified by our model. For this model the area under the ROC curve is 0.80 . Given the cross-sectional nature of our data, this indicates that the estimated model exhibits good predictive ability. ${ }^{8}$

\section{[Figure 1 in about here]}

In Table 2 we report, for the restricted Logit model, the estimated coefficients, their standard errors, and the p-values indicating the impact of different variables upon being an adopter rather than a non-adopter. The last three columns report the odds ratios (as well as the end points of their relative $95 \%$ confidence interval), indicating for each covariate the relative difference between the odds in the relevant category (user) and the base category (non-users).

\section{[Table 2 in about here]}

The empirical evidence confirms that rank effects are important factors in explaining the extent of inter-firm diffusion in 2000. Firm size, whether the firm carries out R\&D, education/skills, and the use of other innovative management and organisational practices have positive and significant impacts. The introductions of product and process innovations by the firm have positive coefficients but both have high standard errors (although the former is below our threshold for significance). There is some evidence that environmental factors play a role (see SIC 15-22 and SIC 60-64).

\footnotetext{
${ }^{8}$ Assuming that $p_{\mathrm{j}}$ is the predicted probability of a positive outcome and $y_{\mathrm{j}}: y_{\mathrm{j}} \in(0,1)$ the actual outcome, a prediction is classified as positive if $p_{\mathrm{j}}>c$ (for $0 \leq c \leq 1$ ) and negative otherwise. In Figure 1 the curve starts at $(0,0)$, corresponding to $c=1$, and continues to $(1,1)$, corresponding to $c=0$. In general, a model with no predictive power would be a $45^{\circ}$ line, so the greater the area under the curve the greater the predictive power of the model.
} 
The inter-industry use variable, reflecting the impact of the extensive margin elsewhere in the industry, carries a positive and significant coefficient. The estimate of the impact of the industry's intensive margin on the firm's extensive margin is a new result, and with a significant positive coefficient implies that greater levels of intra-firm usage in the industry have similarly signed effects on the external margin as do greater levels of inter-firm usage. Jointly the results suggest that any (negative) stock and order effects are outweighed by (positive) epidemic learning and network effects, although we cannot say if the non-market intermediated externalities (epidemic effects) or the market intermediated (stock, order and network effects) are the dominant externalities in the inter-firm diffusion of e-business.

\subsection{Extensive and intensive margins in e-business activities}

In order to highlight the intensive margin we have decomposed the dependent variable $\mathrm{x}(\mathrm{t})$ (see equation 3) into three mutually exclusive categories reflecting the adoption decision and the intensity of use of e-business by the adopting firms. The firm is defined as being in category 0 if a non-adopter, category 1 if a basic user and category 2 if an enhanced user.

A multinomial logit specification has been chosen to best reflect the nature of the firm's mutually exclusive choices where distance (from 0 to 1 and 1 to 2 ) is not necessarily symmetric or where adoption is not necessarily sequential or 'ordered'. Alternative models such as nested or ordered logit models were also estimated, but turned out to be unsuitable or did not outperform the multinomial logit model (further details are available upon request).

In order to rule out criticisms based upon the potential endogeneity problem, we pursue a suggestion of Burke et al. (1992) and employ a modified version of Utts' Rainbow test (Utts, 1982). ${ }^{9}$ The test involves partitioning the total sample into a number of sub-samples and comparing the sum of the squared residuals derived from estimation using all the sample observations to the corresponding quantity obtained using only a partition of the sample ${ }^{10}$. Let $k_{i}$ (for $i=1, \ldots, n$ ) be the covariate under consideration, $L_{0}$ the maximised log-likelihood using the full sample of observations and $L_{r}(r=1, . ., R)$ the corresponding function obtained by estimation using only the $r^{\text {th }}$ sub-sample of reordered data. Under the null hypothesis of

\footnotetext{
${ }^{9}$ It has been suggested to us that there would be some advantages in lagging or instrumenting certain variables in the estimation of this model to overcome potential endogeneity problems. The possibilities of doing so with the CIS3 are limited while merging the CIS2 and CIS3 gives a longitudinal sample of only $10 \%$ the size of the observed CIS3 sample (of whome $31 \%$ did not report on Internet usage) Therefore we did not explore this possibility further.

${ }^{10} \mathrm{We}$ are grateful to Les Godfrey for his useful advice and discussions on this type of endogeneity test.
} 
exogeneity the i.i.d. observations can be ranked by increasing values of $k_{i}$ without affecting the validity of conventional large sample procedures. Thus, the resulting statistic $L R_{R}=-2\left[\widehat{L}_{0}-\sum_{r=1}^{R} \widehat{L}_{r}\right]$ is asymptotically $\chi^{2}$ distributed with degrees of freedom equal to $v=(q-1) \times p$ (where $q$ is the number of categories and $p$ is the number of parameters to be estimated). In Table 3 we report the estimated $p$-value for the $L R_{R}$ test calculated for the different covariates.

\section{[Table 3 in about here]}

In Table 3 the covariate Employ has not been tested for endogeneity on the grounds that by using the figures for 1998 to measure firm size we have ruled out the possibility of endogeneity for this variable. As far as the other covariates are concerned, the modified Utts' rainbow test suggests that we cannot reject the null of exogeneity for any of the potentially exogenous and weakly exogenous variables for either the single logit specification or its multinomial counterpart.

For the multinomial model the predictive power has again been determined estimating the ROC (Receiver Operating Characteristic) curve, this time however for both non-users versus basic users and non-users versus enhanced users. In Figure $2 \mathrm{a}(2 \mathrm{~b})$, we report on the y-axis the 'Sensitivity' measured by the fraction of basic users $x_{\mathrm{j}}=1$ (advanced users, $x_{\mathrm{j}}=2$ ) correctly classified while on the $\mathrm{x}$-axis we report '1-Specificity' measured as the fraction of non-users, $x_{\mathrm{j}}=0$ (basic users, $x_{\mathrm{j}}=1$ ) wrongly classified by our model. In our case the areas under the ROC curve are 0.76 and 0.81 , respectively indicating good predictive ability. However, the Q-Q plot of the quantiles of the deviance residuals against the quantiles of the normal distribution reported in Figure 3 show some marginal sign of kurtosis in the tails.

\section{[Figures 2 and 3 about here]}

The coefficients of the multinomial specification are reported in Table 4 and are to be read in the top half of the table as indicating the impact of different variables upon being a non-user rather than a basic user, and in the bottom half of being an enhanced user rather than a basic user. The last three columns of the table report the odds ratios (as well as the end points of their relative 95\% confidence interval), indicating for each covariate the relative difference between the odds in the relevant category and the base category (basic users). 


\section{[Table 4 in about here]}

Interpreting the estimated parameters, firm size as measured by Employ impacts negatively and significantly on the probability of being a non-user (i.e. larger firms are less likely to be non-users) than a basic user. This is in line with the findings of the inter-firm diffusion literature (see also Table 2). We see also that enhanced usage is negatively related to firm size and thus large firms are less likely to be enhanced users; however, the estimated coefficient is very small and insignificant. This implies that large firms are more likely to adopt e-business but do not necessarily have faster intra-firm diffusion. In other words, enhanced usage is not the prerogative of large firms. This is a result also found by Battisti (2000) for the intra-firm diffusion of other technologies.

Although Procnov and Prodnov, indicating the introductions of product and process innovations, impact negatively on the probability of being a non-user, in both cases the $p$ value exceeds 0.25 and is not significant. Procnov and Prodnov impact positively and significantly on enhanced usage, however, Prodnov has only limited significance. On the other hand Mngt, Org, $R \& D$ all impact negatively on non-usage and positively on enhanced usage and are significant. Overall these results generally support a view that a firm that is innovative in one dimension (technological or organisational) may also be innovative in another, i.e. in the adoption and enhancement of e-business usage.

The skills variables PropOth and PropSci have a negative and significant effect on non-use and thus a greater proportion of graduates leads to a higher probability of basic use. For enhanced use both variables show positive coefficients but are not significant. The same can be said on the basis of the corresponding odds ratios, which are not significantly different from unity. This is consistent with a view that skills, as measured by the two variables available, are important for first adoption but they are not a discriminating factor in the decision to extend e-business use.

The sign of Inter and Intra are both negative and significant in the non-users results, implying that more adopters and more intensive use encourage basic use (although when instrumented with the CIS2 data Inter becomes non-significant). This is consistent with epidemic and/or network effects being dominant over stock and order effects although it tells us nothing of the relative size of market and non-market intermediated externalities. With respect to enhanced use, Inter carries a negative coefficient and Intra a positive coefficient, both significant. Thus wider inter-firm adoption discourages further enhanced use, whereas more enhanced use by adopting firms encourages further enhanced use. A possible explanation is that greater 
enhanced use by others (for a given external margin) has a demonstration or network benefit to the firm, but more users for a given degree of enhancement (internal margin) has a competitive downward impact upon returns to enhancement. Once again however both market intermediated and non-market intermediated externalities may be present.

In summary the estimates indicate that factors particularly quantitatively important in encouraging basic use as opposed to non-use are firm size, other indicators of innovativeness (but not ProdNov or ProcNov), the proportion of graduates employed, and usage by other firms at basic and enhanced levels. Factors particularly important in driving enhanced use as opposed to basic usage are a number of indicators of innovativeness such as Mngt, Org, R\&D including ProcNov, but firm size, despite being an important factor in determining basic use (or use per se, see Table 2), has an insignificant (but negative) effect on the likelihood of becoming an enhanced as opposed to a basic user. The proportion of other enhanced users in the industry impacts positively on the intensive margin but the total proportion of e-business adopters in the industry (Inter) exerts a significant negative effect upon the within-firm extent of further use. Therefore, the increasing number of e-business users stimulates further ebusiness adoption but at the same time it slows down the extent of intra-firm e-business use by the adopting firms. This would not have been observed from standard modelling as per Table 2, where Inter and Intra both have significant positive effects.

Finally, we have tested whether the odds ratios in the multinomial model are independent of the other choices (i.e. independence of disturbances across the different choices) by carrying out the Independence from Irrelevant Alternatives (IIA) test (see Hausman and McFadden, 1984). The result from the omission of the non-users category (0) yields $\chi^{2}=1.538$ $\left(\chi_{v=3, p=5 \%}^{2}=7.815 ; p=0.674\right)$, suggesting that the choice to be a basic user with respect to an enhanced user is independent of the firm decision to adopt the technology. This is consistent with the findings of Battisti (2000) and Battisti and Stoneman $(2003,2005)$ that the intra-firm adoption decision is independent of the inter-firm adoption decision and also rules out the possibility that a nested logit model would have been better than the multinomial model.

\section{POLICY IMPLICATIONS}

Although there are some differences in the results of the inter-firm model and the integrated model the results above indicate that the diffusion of e business process of e-business reflects that: 
(i) firms of different characteristics obtain different returns from using or extending usage of new technology (rank effects), as evidenced by the impact upon basic and enhanced usage in 2000 of firm size, other indicators of innovativeness and industry dummies.;

(ii) there may be market intermediated stock, order or network effects, as well as nonmarket intermediated spillovers (epidemic effects) as indicated by the significance of inter and intra on both basic and enhanced use, although there is no agreement as to which of these effects are dominant .

These findings extend to the intensive margin arguments previously reserved for the extensive margin. Building upon these findings we now explore policy implications. This discussion concentrates upon rationales for policy rather than policy instruments in order to save space.

To explore implications of the results as regards the need for policy first we consider rank effects and then externalities (stock, order, network and epidemic effects). An initial point to note is that by the year 2000 the inter-firm diffusion process for e-business was pretty much complete (in excess of $80 \%$ of firms were users). However intra-firm usage is still quite limited. If policy is to stimulate usage there is thus much more to do to encourage enhancement rather than basic use. We believe that this is common to many technologies after their early years (Battisti and Stoneman, 2003).

The importance of rank effects indicates that the patterns of both inter- and intra-firm diffusion reflect the different benefits and returns obtained by firms of different characteristics. The underlying rationale for this according to our model is that to some degree (at least) different firms get different net payoffs from technology usage. This finding has an initial message viz. that potential users of a technology may be heterogeneous in various characteristics that affect the size of the profit to be gained (for a wider discussion of such issues see David, 2003). Current users will be those that have seen that the technology can yield a profit gain and have thus adopted. This does not necessarily mean that such gains are available to non-users of different characteristics. Non-users may well be non-users because the technology does not yield them a profit gain. To justify intervention and to stimulate further usage on the grounds that past adopters have gained profits from use of a new technology is thus not sufficient.

More formally, Ireland and Stoneman (1986) explore a rank effect inter-firm model to which an intertemporally profit-maximising supply sector is added. They show that if the supply sector is monopolised then its pricing will generate diffusion that is welfare-optimal if the buyers have myopic price expectations but a path involving diffusion that is slower than is 
welfare-optimal if buyers have perfect foresight. If the supply sector is competitive then diffusion would be welfare-optimising under perfect foresight but too fast under myopia.

It would appear that this argument can be extended to incorporate issues of intra-firm diffusion, although we do not intend to do that formally here. The need for intervention in both inter- and intra-firm diffusion processes in a world where rank effects are important is thus a matter of the structure of the supply industry (which can be observed) and the nature of firms' technological expectations (which cannot).

As regards externalities, Laffont (1988) defines an externality as

“... the indirect effect of a consumption activity or a production activity on the consumption set of a consumer, the utility function of a consumer or the production function of a producer. By indirect we mean that the effect concerns an agent other than the one exerting this economic activity and that this effect does not work through the price system."

The Laffont (1988) definition rules out as externalities two types of effects that are part of our model. The first are intra-firm intertemporal effects, whereby (for example) learning from own current experience or the impact on future profit gains from current adoption affect the firm's own future decisions. This is reasonable for these are expected to be taken account of in the firm's own decision-making. Secondly, the definition rules out effects that work through the price system. Thus the impact of $y_{j}(t)$ on the payoff to firm $i$ (between firm stock, order and network effects) is not to be considered as an externality. On the other hand interfirm learning is not intermediated by the market but is a classic externality and is to be treated as such. Kaivanto (2004) provides a useful classification between 'pecuniary externalities' and 'technological externalities' where pecuniary externalities (sometimes called distributional externalities) are external effects intermediated by the market and encompass the stock and order effects. Network externalities which arise from the benefits to users from larger networks will also fall into this category. Technological externalities (sometimes called real income externalities) are the other effects that are not so intermediated (and encompass the learning effects, $\left.E_{j}(t)\right)$.

The presence of technological externalities (externalities transmitted outside the market system) provides an unambiguous signal of incomplete private appropriation of the costs and or benefits of the firm's actions. If one firm's behaviour causes a non-appropriated benefit to another firm by, for example, improving that other firm's knowledge base, then the true social 
benefits of the actions are not gained by the decision-maker and there will be underinvestment in the new technology. The diffusion path will be sub-optimal.

It is argued however that pecuniary externalities (those transmitted by the price system) do not imply market failure. Scitovsky (1954) shows that the addition of pecuniary externalities to the assumptions underpinning a perfect market does not result in a Pareto-inferior equilibrium.

However Laffont (1988) shows that if the market for contingent claims is incomplete - as one might expect generally to be the case, then pecuniary externalities do detract from social welfare. However Loong and Zeckhauser (1982) show that the associated decisions do not display a systematic bias ex ante, they may be either over-cautious or over-risky and thus in our context there may have been over- or under-investment in the new technology (see Kaivanto, 2004).

One might also argue that pecuniary externalities are the prerogative of oligopolistic markets. Such effects imply that one firm's adoption of a new technology will reduce (or in the case of some network technologies even increase) the potential return to another adopter, through the impact upon either market prices or input costs. In a perfectly competitive world such pecuniary externalities would not exist. All firms would be price takers and no firm's actions would be important enough to affect the market. As oligopolistic markets will already be not at the social optimum, whether the market is over- or under-investing in new technology is generally not possible to say.

Although our empirical results are not definitive, they do indicate that there are probably technological externalities in the diffusion of e-business in the UK. This is reflected in the significant positive sign on the measured coefficient of Inter and Intra on basic use and Intra on enhanced use (which if not reflecting technological externalities must represent a very strong positive network externality). As detailed above it is generally accepted that in the presence of such externalities economic actors will not be able to appropriate the full social costs and benefits of their actions and thereby their decisions will be sub-optimal - a market failure will exist. In general diffusion will be too slow. Government intervention will be recommended.

Our analysis above does not rule out that pecuniary externalities may also exist. Although it is less well accepted, as discussed above, this may also imply a case for intervention. There may also be other market failures in the economy that would affect the optimality of the diffusion 
path, for example there may be monopoly power in factor markets. It might also be the case that the whole national system of innovation in the economy needs improvements to (for example) training and education, capital markets, taxation regimes, corporate governance. Such issues however, although important, are beyond the scope of this paper.

\section{CONCLUSIONS}

Using enterprise-level data from the third Community Innovation Survey this paper maps out the pattern of basic and enhanced e-business usage in the UK in 2000. The existing diffusion literature largely concentrates upon the extensive margin (inter-firm diffusion) whereas here we emphasise in addition the intensive margin (the intra-firm aspect).

The data show that the extent of inter-firm diffusion is not necessarily a good predictor of the extent of intra-firm diffusion. Although by $200083.2 \%$ of sample firms were users, only $25.6 \%$ were enhanced users. Further usage must thus concentrate upon greater depth (enhancement) rather than greater breadth (further spreading of basic usage).

We have constructed a joint model of inter- and intra-firm diffusion and estimated it as both (i) a traditional model of use/non-use and (ii) a joint model of use and the extent of use. Empirically, we have found differences in the way in which the four classes of hypothesised drivers of diffusion affect the extensive margin (inter-firm diffusion) and intensive margin (intra-firm diffusion).

A number of rank effects, reflecting differences between firms, are found to be significant, but the direction and the intensity of their impact upon inter- and intra-firm diffusion is not always the same (as seen for example with the firm-size effect). Stock, order, network and epidemic effects are reflected in the impact of the within-industry number of adopters and other firms' usage (both intra- and inter-firm indicators being used to measure this) on individual adoption and extent of use. Both non-market mediated externalities (such as epidemic learning) as well as market mediated pecuniary externalities (such as stock effects) are considered to affect the firm's extent of use.

The results with respect to e-business provide a basis upon which to build a more general discussion of the needs of diffusion policy. Our results indicate that adoption and therefore basic usage of e-business was already widespread by 2000 and thus intervention in diffusion processes, except in the very early years, may well be most effectively directed at the enhancement of use (which is exactly the aspect about which we know least). We have 
isolated rank effects as significant explanations of enhanced usage and thus it is not necessarily the case that all basic users can make a gain from enhanced usage. However there may be social gains from stimulating enhanced usage.. Technological externalities may also play a role in the spread of basic and enhanced e-business usage. This is a classic rationale for market failure and would suggest intervention. Finally there may also be pecuniary externalities but we are unable to say whether this implies diffusion that is too extensive or too limited.

Acknowledgements We would like to thank participants in the Workshop on Information Technology and the New Industry and Labour Market Dynamics, MERIT Maastricht, 3-4 June 2004, the European Network for Industrial Policy (EUNIP) Conference, Birmingham University, 13-15 December 2004, the NIE Winter Conference of the Network of Industrial Economists, University of Nottingham, 14 December 2004, the bi-weekly Industrial Organization Workshop in the Department of Economics, Warwick University, the staff seminar in the Economics and Finance department at London Metropolitan University, and two referees and the editor of Research Policy for their useful comments on earlier versions of this paper. Of course all errors and omissions that remain are the responsibility of the authors alone.

\section{REFERENCES}

Astebro, T., 2002. Non-capital Investment Costs and the Adoption of CAD and CNC in US Metalworking Industries, RAND Journal of Economics, Winter 2002, 33, 4, 672-688.

Bartel, A. and F. R. Lichtenberg, 1987. The Comparative Advantage of Educated Workers in Implementing New Technology, Review of Economics and Statistics, LXIX, 1- 11.

Battisti, G., 2000. The Intra-Firm Diffusion of New Technologies, PhD Thesis, Warwick University.

Battisti, G, H. Hollenstein, P. Stoneman and M. Woerter, 2007. Inter- and Intra-firm Diffusion of ICT in the United Kingdom UK. and Switzerland CH. An Internationally Comparative Study Based on Firm-level Data, Economics of Innovation and New Technology 16, 8, 2007, 669.

Battisti, G. and P. Stoneman, 2003. Inter Firm and Intra Firm Effects in the Diffusion of New Process Technologies, Research Policy 32, 1641-1655.

Battisti, G. and P. Stoneman, 2005. The intra-firm diffusion of new process technologies, International Journal of Industrial Organization 23, 1-22. 
Black S. E. and L. Lynch, 2004. Whats Driving the New Economy? The Benefits of Workplace Innovation, Economic Journal, 114493, 97-116

Bresnahan, T. F., Brynolfsson, E. and L. M. Hitt, 2002. Information Technology, Workplace Organisation and the Demand for Skilled Labour; Firm-Level evidence, Quarterly Journal of Economics, 117, 339 - 376.

Bridgewater, S. and D. Arnott, 2004. The Internet and International Markets: Benefits and Barriers, Academy of International Business Conference, June.

Brynjolfsson E, Hitt L. M., Yang S., 2002. Intangible Assets: Computers and Organizational Capital, Brookings Papers on Economic Activity 1, 137-81

Burke, L., Godfrey L.G., Mealier, M. 1992. Modification of the Rainbow Test. In The Implementation and Constructive Use of Misspecification Tests in Econometrics. Manchester University Press, Manchester.

Canarias, G., Colombo, M. G. and S. Mariotti, 1990. Firm Size and the Adoption of Flexible Automation, Small Business Economic, 2, 129-140.

Caroli, E. and J. Van Renan, 2001. Skill Biased Organizational Change? Evidence from a Panel data of British and French Establishments Quarterly Journal of Economics 116, $1447-1492$.

Cohen, W. and D. Levinthal, 1989. Innovation and Learning: the Two faces of R\&D, Economic Journal 99, 569-96.

Colombo, M. and R. Mosconi, 1995. Complementarily and Cumulative Learning Effects in the Early Diffusion of Multiple Technologies, The Journal of Industrial Economics 63, $11,13-48$.

Crespi G., Mahdi S., and P. Patel, 2004. Adoption of E-commerce Technology: Do Network and Learning Externalities Matter?, SPRU, University of Sussex.

David, P., 2003. Zvi Griliches on Diffusion, Lags and Productivity Growth, connecting the dots, paper presented at the Conference on $R \& D$ Education and Productivity, held in memory of Zvi Griliches 1930 - 1999., Paris, August, 2003 this draft December.

Finegold, D. and Soskice, D. 1988. The failure of British training: analysis and prescription, Oxford Review of Economic Policy 4, 3, 21 -53.

Forman, C., Goldfarb, A., and S. Greenstein, 2002. Digital Dispersion: An Industrial and Geographic Census of Commercial Internet Use, NBER WP 9287, Oct.

Forman, C., Goldfarb, A., and S. Greenstein, 2003. How did Location Affect Adoption of the Commercial internet: Global Village, Urban Density and Industry Composition, NBER WP 9979, Sept.

Fudenberg, D. and J. Tirole, 1985. Pre-emption and Rent Equalisation in the Adoption of New Technology, Review of Economics Studies 52, 383 - 401. 
Green, D. M. and J. A. Swets, 1974. Signal Detection Theory and Psychophysics, Rev. Ed. Huntington, NY: Krieger.

Greenan, N., 2003. Organisational change, technology, employment and skills: An empirical study of French manufacturing, Cambridge Journal of Economics 27, 287-316.

Hall, B., 2004. Innovation and Diffusion, NBER Working Paper No.10212, NBER, Cambridge Mass.

Hannan, T. H. and J. M. McDowell, 1984. The Determinants of Technology Adoption: the Case of the Banking Firm, RAND Journal of Economics 15, 328-335.

Hausman J. and McFadden, 1984. A Specification Test for the Multinomial Logit Model Econometrica 52, 1219-1240.

Hollenstein, H., 2004. Determinants of the Adoption of Information and Communication Technologies ICT.: An Empirical Analysis based on firm level data for the Swiss business sector, Structural Change and Economic Dynamics 15, 315 - 342.

Ireland, N. and P. Stoneman, 1986. Technological Diffusion, Expectations and Welfare, Oxford Economic Papers 38, 283 -304

Kaivanto, K., 2004. Spin Offs, Externalities and the Economic Justification of Public Expenditure on R\&D, Lancaster University, January

Karshenas, M. and P. Stoneman, 1993. Rank, Stock, Order and Epidemic Effects in the diffusion of new process technologies: an Empirical Model, RAND Journal of Economics $24,4,503-28$.

Karshenas, M. and P. Stoneman, 1995. Technological Diffusion in P. Stoneman (Ed). Handbook of the Economics of Innovation and Technological Change, Blackwell, Cambridge.

Laffont, J-J., 1988. Fundamentals of Public Economics, MIT Press, Cambridge, Mass.

Loong, L.H. and R. Zeckhauser 1982.Pecuniary Externalities Do Matter When Contingent Claim Markets Are Incomplete, Quarterly Journal of Economics 97, 171 - 179

Mansfield, E., 1963. Intrafirm Rates of Diffusion of an Innovation, The Review of Economics and Statistics, 495, 348-359.

Mansfield, E., 1968. Industrial Research and Technological Innovation, W.W. Norton, New York.

Mickey, J. and S. Greenland, 1989. A study of the Impact of Confounder-Selection Criteria on Effect Estimation. American Journal of Epidemiology 129, 125-137.

Pil, T.D. and P. MacDuffie 1996. "The adoption of high involvement work practices", Industrial Relations 35, 423-455.

Reinganum, J, 1981. The Diffusion of New Technology and the Market for an Innovation, Rand Journal of Economics 17, 33-47. 
Scitovsky, T., 1954. Two Concepts of External Economies, Journal of Political Economy 62, $143-151$.

Stoneman, P., 1981., Intra Firm Diffusion, Bayesian Learning and Profitability, Economic Journal 91, 375-388.

Stoneman, P. and G. Battisti, 1997. Intra-firm Diffusion of New Technologies: the Neglected Part of Technology Transfer International Journal of Industrial Engineering 4, 2, $270-82$.

Utts, J.M., 1982. The rainbow test for lack of fit in regression. Communication in Statistics: Theory and Methods 11, 2801-15. 
APPENDIX 1: 1992 SIC CODES BY WIDE INDUSTRY GROUPING.

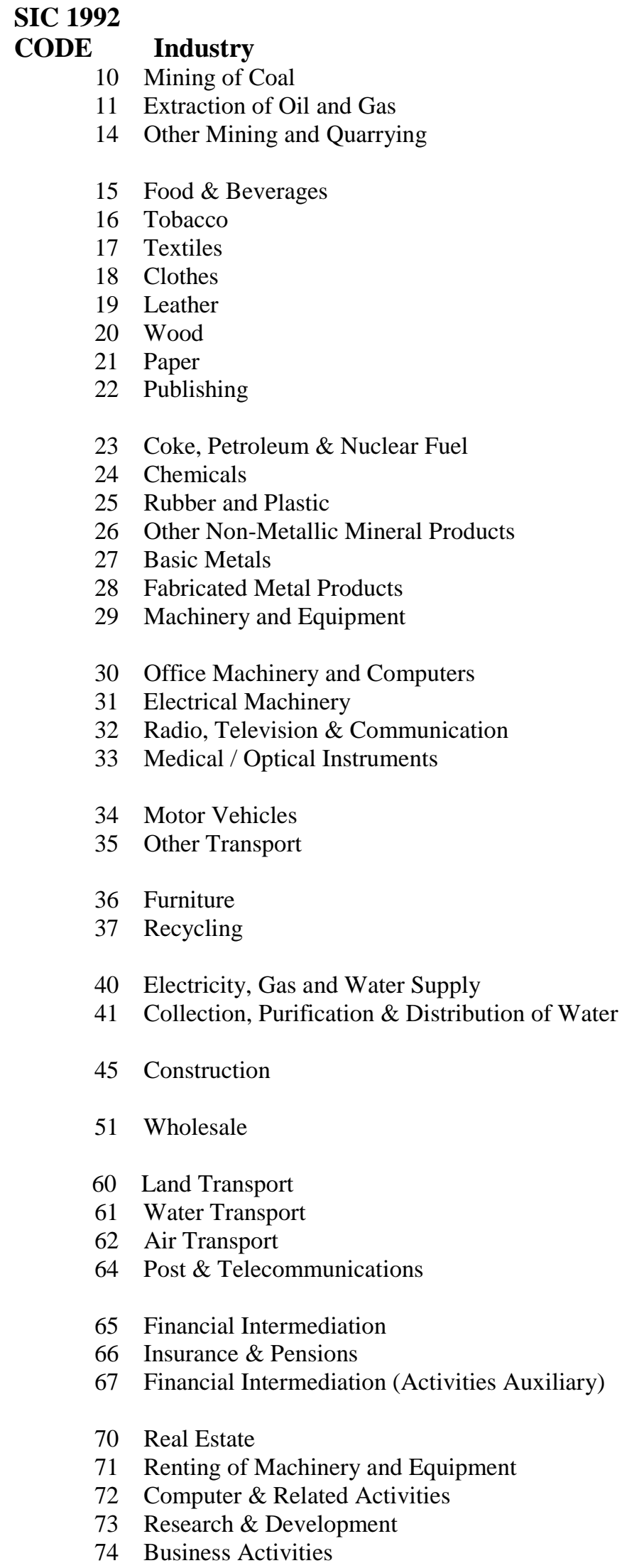


Table 1: Patterns of e-business usage, UK, 2000

\begin{tabular}{|c|c|c|c|c|c|}
\hline & & \begin{tabular}{|c|}
$\begin{array}{c}\text { Non-users } \\
(\%)\end{array}$ \\
\end{tabular} & \begin{tabular}{|c|}
$\begin{array}{c}\text { Basic users } \\
(\%)\end{array}$ \\
\end{tabular} & $\begin{array}{l}\text { Enhanced } \\
\text { users (\%) }\end{array}$ & $\begin{array}{c}\text { Row Total }=100 \% \\
\text { no. }\end{array}$ \\
\hline All firms & & 16.8 & 57.53 & 25.63 & 8173 \\
\hline Within-ir & dustry distribution of use ( & within-indus & stry proportio & of adopters & \\
\hline SIC 92 & description & & & & \\
\hline $10-14$ & Mining and quarrying & 22.0 & 66.9 & 11.0 & 127 \\
\hline $15-22$ & $\begin{array}{l}\text { Manufacturing of food, } \\
\text { clothing, wood, paper, } \\
\text { publishing \& printing }\end{array}$ & 17.8 & 56.3 & 25.9 & 1005 \\
\hline $23-29$ & $\begin{array}{l}\text { Manufacturing of fuels, } \\
\text { chemicals, plastic metals \& } \\
\text { minerals }\end{array}$ & 14.5 & 56.6 & 28.9 & 1121 \\
\hline $30-33$ & $\begin{array}{l}\text { Manufacturing of electrical and } \\
\text { optical equipment }\end{array}$ & 5.1 & 63.4 & 31.5 & 527 \\
\hline $34-35$ & $\begin{array}{l}\text { Manufacturing of transport } \\
\text { equipment }\end{array}$ & 8.1 & 66.6 & 25.3 & 344 \\
\hline $36-37$ & $\begin{array}{l}\text { Manufacturing not elsewhere } \\
\text { classified }\end{array}$ & 16.0 & 65.5 & 18.5 & 443 \\
\hline $40-41$ & Electricity, gas \& water supply & 13.2 & 62.3 & 24.5 & 53 \\
\hline 45 & Construction & 28.8 & 57.1 & 14.0 & 947 \\
\hline 51 & $\begin{array}{l}\text { Wholesale Trade (incl. cars \& } \\
\text { cycles) }\end{array}$ & 16.5 & 54.9 & 28.6 & 1041 \\
\hline $60-64$ & $\begin{array}{l}\text { Transport, storage \& } \\
\text { communication }\end{array}$ & 20.3 & 50.5 & 29.2 & 773 \\
\hline $65-67$ & Financial intermediation & 13.3 & 54.3 & 32.3 & 405 \\
\hline $70-74$ & $\begin{array}{l}\text { Real estate, renting \& business } \\
\text { activities }\end{array}$ & 15.7 & 58.3 & 26.0 & 1386 \\
\hline & Total & 16.8 & 57.5 & 25.6 & 8173 \\
\hline Usage b & y size (number of employee & & & & \\
\hline & $10-49$ & 22.9 & 53.5 & 23.7 & 4761 \\
\hline & $50-249$ & 9.4 & 65.2 & 25.3 & 2023 \\
\hline & $250-499$ & 6.5 & 62.3 & 31.2 & 722 \\
\hline & $500-999$ & 7.5 & 60.9 & 31.6 & 402 \\
\hline & $1000_{+}$ & 6.4 & 53.8 & 39.8 & 264 \\
\hline & Total & 16.8 & 57.5 & 25.6 & 8173 \\
\hline
\end{tabular}


Table 2. The extensive margin: results of fitting a logistic model

\begin{tabular}{|c|c|c|c|c|c|c|c|}
\hline \multirow{3}{*}{$\begin{array}{l}x_{\mathrm{j}} \\
p \text { ploy }\end{array}$} & \multirow{3}{*}{$\begin{array}{c}\text { Coef. }{ }^{a} \\
\mathbf{0 . 0 3 9}\end{array}$} & \multirow{3}{*}{$\begin{array}{l}\text { Std. } \\
\text { Err. } \\
\mathbf{0 . 0 0 5}\end{array}$} & \multirow{2}{*}{$\begin{array}{c}\text { Wald } \\
\text { Test } \\
\end{array}$} & \multirow{2}{*}{$P>z$} & \multicolumn{3}{|c|}{ Odds Ratios } \\
\hline & & & & & \multirow{2}{*}{$\begin{array}{l}\text { Value } \\
1.040\end{array}$} & \multicolumn{2}{|c|}{$[95 \% \text { C.I }]^{c}$} \\
\hline & & & 7.660 & 0.000 & & 1.030 & 1.050 \\
\hline rocNov & 0.324 & 0.331 & 0.980 & 0.326 & 1.383 & 0.724 & \\
\hline DrodNuv & 0.451 & 0.287 & 1.570 & 0116 & 1.570 & & \\
\hline$\& D$ & 0.804 & 0.176 & 4.580 & 0.0 & & & \\
\hline Ingt & 539 & 151 & 3.560 & 0.000 & 1.714 & .274 & \\
\hline rg & 313 & 0.149 & 5.440 & 0.000 & 2.254 & 1.681 & 21 \\
\hline PropOth & 0.008 & 0.003 & 2.540 & 0.011 & 1.008 & 1.002 & 1.014 \\
\hline PropSci & 0.047 & 0.009 & 5.340 & 0.000 & 1.049 & 1.031 & 1.067 \\
\hline Sic15-22 & -0.248 & 0.142 & -1.750 & 0.081 & 0.780 & 0.591 & 1.031 \\
\hline Sic23-29 & -0.157 & 0.157 & -1.000 & 02 & 0.854 & 0.628 & 1107 \\
\hline Sic 36-37 & -0.049 & 0.213 & -0.230 & 10 & 952 & 628 & \\
\hline Sic60-64 & -0.404 & 0.174 & 2.320 & 0.020 & .667 & 0.474 & 0.939 \\
\hline Sic65-67 & 0.001 & 0.260 & 0.000 & 0.996 & 1.001 & 0.602 & 1.665 \\
\hline Inter & 0.488 & 0.207 & 2.360 & 0.018 & 1.629 & 1.086 & 2.443 \\
\hline Intra & 0.808 & 0.139 & 5.810 & 0.000 & 2.244 & 1.709 & 2.948 \\
\hline 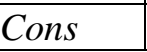 & 73 & 0.392 & 2.990 & 0.003 & & & \\
\hline
\end{tabular}

NOTE: Number of observations $=5822 . L R \chi^{2}(15)=684.28$ (p-value: 0.000$) . L o g ~ L i=-1678.57$

${ }^{\mathrm{a}}$ Comparison group $=$ non-users. ${ }^{\mathrm{b}}$ Odds ratio confidence intervals that include unity indicate that the odds ratio of the covariate in the relevant category (users) is not different from the odds ratio in the base category (non- users). Odds ratios significantly different from 1 in bold.

Table 3. Estimated $p$-values for the likelihood ratio test (nominal size 5\%).

\begin{tabular}{|l|c|c|}
\hline & \multicolumn{2}{|c|}{$P\left(L R \geq L R_{R}\right)$} \\
\hline$x_{i}$ & Simple Logit model & Multinomial model \\
\hline Mngt & 0.005 & 0.010 \\
\hline Org & 0.005 & 0.010 \\
\hline ProdNov & 0.005 & 0.010 \\
\hline ProcNov & 0.005 & 0.010 \\
\hline R\&D & 0.005 & 0.010 \\
\hline PropSci & 0.000 & 0.000 \\
\hline PropOth & 0.000 & 0.000 \\
\hline
\end{tabular}


Table 4. Result of fitting a multinomial logistic regression model

\begin{tabular}{|c|c|c|c|c|c|c|c|c|}
\hline \multirow[b]{3}{*}{ Non Users } & \multirow{2}{*}{$x_{\mathrm{j}}$} & \multirow{2}{*}{ Coef. ${ }^{a}$} & \multirow{2}{*}{$\begin{array}{l}\text { Std. } \\
\text { Err. }\end{array}$} & \multirow{2}{*}{$\begin{array}{l}\text { Wald } \\
\text { Test }\end{array}$} & \multirow{2}{*}{$P>z$} & \multicolumn{3}{|c|}{ Odds Ratios } \\
\hline & & & & & & Value & \multicolumn{2}{|c|}{$[95 \% \text { C.I }]^{c}$} \\
\hline & Employ & -0.016 & 0.003 & \begin{tabular}{|l|}
-5.860 \\
\end{tabular} & 0.000 & 0.984 & 0.979 & 0.990 \\
\hline & ProcNov & -0.123 & 0.298 & \begin{tabular}{|l|}
-0.410 \\
\end{tabular} & 0.680 & 0.884 & 0.493 & 1.585 \\
\hline & ProdNov & -0.215 & 0.244 & \begin{tabular}{|l|}
-0.880 \\
\end{tabular} & 0.378 & 0.807 & 0.500 & 1.301 \\
\hline & $R \& D$ & -0.568 & 0.155 & -3.670 & 0.000 & 0.567 & 0.418 & 0.768 \\
\hline & Mngt & -0.494 & 0.144 & -3.440 & 0.001 & 0.610 & 0.460 & 0.809 \\
\hline & Org & -0.678 & 0.139 & -4.890 & 0.000 & 0.508 & $\mathbf{0 . 3 8 7}$ & 0.666 \\
\hline & PropOth & -0.007 & 0.003 & -2.450 & 0.014 & 0.993 & 0.987 & 0.999 \\
\hline & PropSci & -0.026 & 0.006 & -4.480 & 0.000 & 0.974 & 0.963 & 0.985 \\
\hline & Sic15-22 & 0.227 & 0.141 & 1.610 & 0.107 & 1.255 & 0.952 & 1.653 \\
\hline & Sic23-29 & 0.251 & 0.150 & 1.680 & $\mathbf{0 . 0 9 3}$ & 1.286 & 0.959 & 1.724 \\
\hline & Sic36-37 & -0.078 & 0.210 & -0.370 & 0.711 & 0.925 & 0.613 & 1.396 \\
\hline & $\begin{array}{l}\text { Sic 60- } \\
64\end{array}$ & 0.428 & 0.173 & 2.480 & 0.013 & 1.535 & 1.093 & 2.153 \\
\hline & Sic65-67 & 0.146 & 0.247 & \begin{tabular}{|l|}
0.590 \\
\end{tabular} & 0.555 & 1.157 & 0.712 & 1.880 \\
\hline & Inter & -0.544 & 0.192 & -2.830 & 0.005 & 0.535 & 0.409 & 0.702 \\
\hline & Intra & -0.625 & 0.138 & \begin{tabular}{|l|}
-4.530 \\
\end{tabular} & 0.000 & 0.581 & 0.398 & 0.847 \\
\hline & Cons & -0.810 & 0.378 & -2.140 & 0.032 & - & - & - \\
\hline \multirow[t]{16}{*}{ Enhanced Users } & Employ & -0.0001 & 0.0002 & \begin{tabular}{|l|}
-0.510 \\
\end{tabular} & 0.609 & 0.999 & 0.999 & 1.000 \\
\hline & ProcNov & 0.499 & 0.117 & 4.270 & 0.000 & 1.647 & 1.310 & 2.071 \\
\hline & ProdNov & 0.122 & 0.100 & 1.220 & 0.222 & 1.129 & 0.929 & 1.373 \\
\hline & $R \& D$ & 0.295 & 0.075 & 3.940 & 0.000 & 1.343 & 1.160 & 1.555 \\
\hline & Mngt & 0.236 & 0.080 & 2.970 & 0.003 & 1.266 & 1.084 & 1.480 \\
\hline & Org & 0.187 & 0.079 & 2.370 & 0.018 & 1.205 & 1.033 & 1.406 \\
\hline & PropOth & 0.002 & 0.002 & 1.070 & 0.286 & 1.002 & 0.998 & 1.005 \\
\hline & PropSci & 0.001 & 0.002 & 0.650 & 0.518 & 1.001 & 0.997 & 1.005 \\
\hline & Sic15-22 & 0.037 & 0.101 & 0.370 & 0.712 & 1.038 & 0.851 & 1.266 \\
\hline & Sic23-29 & 0.000 & 0.094 & 0.000 & 0.997 & 1.000 & 0.832 & 1.201 \\
\hline & Sic36-37 & -0.085 & 0.162 & -0.530 & 0.598 & 0.918 & 0.669 & 1.261 \\
\hline & $\begin{array}{l}\text { Sic 60- } \\
64\end{array}$ & 0.251 & 0.116 & 2.160 & 0.031 & 1.285 & 1.023 & 1.614 \\
\hline & Sic65-67 & 0.113 & 0.144 & \begin{tabular}{|l|}
0.790 \\
\end{tabular} & 0.430 & 1.120 & 0.845 & 1.485 \\
\hline & Inter & -0.216 & 0.088 & -2.450 & 0.014 & 0.806 & 0.678 & 0.958 \\
\hline & Intra & 0.690 & 0.134 & 5.160 & 0.000 & 1.994 & 1.534 & 2.591 \\
\hline & Cons & -0.080 & 0.250 & -0.320 & 0.748 & - & - & - \\
\hline
\end{tabular}

NOTE: Number of observations $=5822 . \operatorname{LR} \chi^{2}(32)=709.04$ ( $p$-value: 0.000). Log Lik. $=-4937.448$. Comparison group $=$ Basic Users. ${ }^{b}$ Odds ratio confidence intervals that include unity indicate that the odds ratio of the covariate in the relevant category is not different from the odds ratio in the base category (i.e. basic users). Odds ratios significantly different from 1 in bold 
Figure 1. Receiver Operating Characteristic (ROC) Curve: inter-firm model

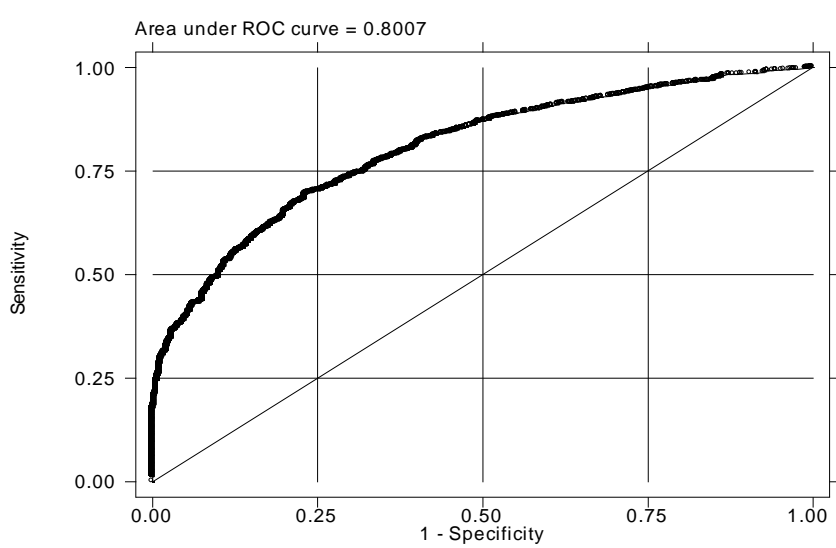

Figure 2. Receiver Operating Characteristic (ROC) Curve: integrated model

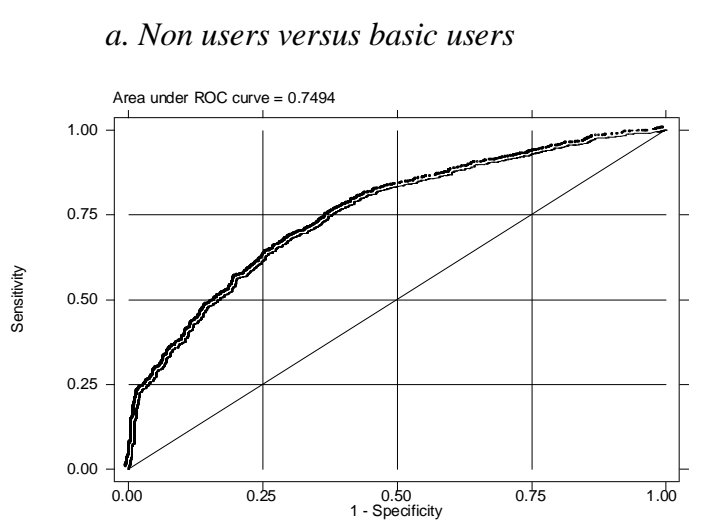

b. Non users versus advanced users

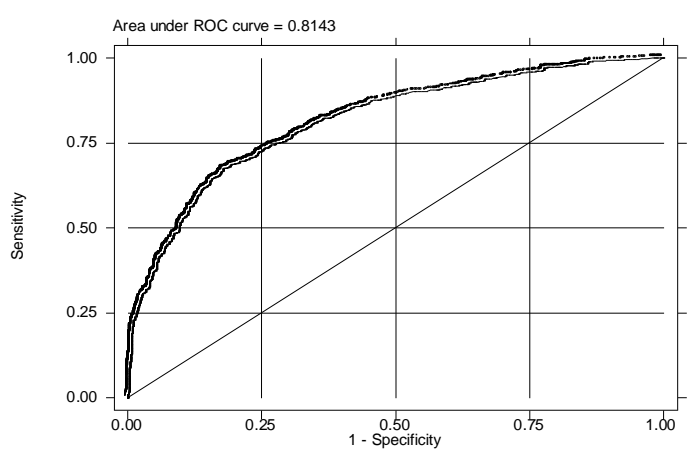

Figure 3. Q-Q plot of deviance residual against the Normal distribution

a. Basic users

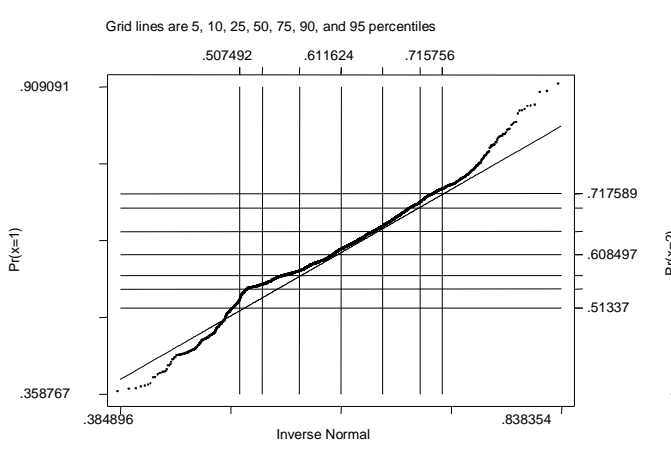

b.Advanced users

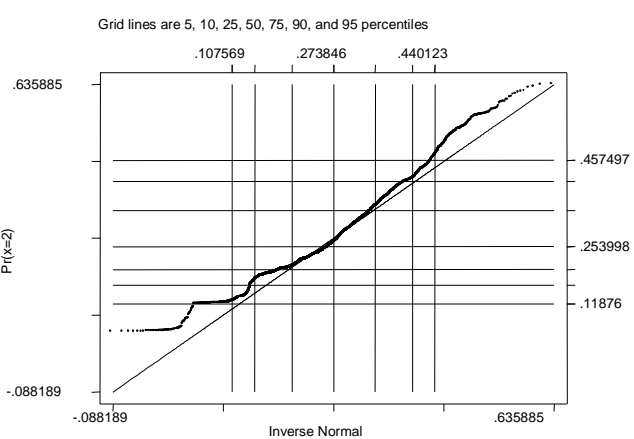

